\section{Cureus}

\title{
Measuring Progress Toward Universal Health Coverage: Does the Monitoring Framework of Bangladesh Need Further Improvement?
}

\author{
Rajat Das Gupta ${ }^{1}$, ASM Shahabuddin ${ }^{1}$ \\ 1. James P Grant School of Public Health, BRAC University
}

$\square$ Corresponding author: Rajat Das Gupta, rajat89.dasgupta@gmail.com Disclosures can be found in Additional Information at the end of the article

\section{Abstract}

This review aimed to compare Bangladesh's Universal Health Coverage (UHC) monitoring framework with the global-level recommendations and to find out the existing gaps of Bangladesh's UHC monitoring framework compared to the global recommendations. In order to reach the aims of the review, we systematically searched two electronic databases - PubMed and Google Scholar - by using appropriate keywords to select articles that describe issues related to UHC and the monitoring framework of UHC applied globally and particularly in Bangladesh. Four relevant documents were found and synthesized. The review found that Bangladesh incorporated all of the recommendations suggested by the global monitoring framework regarding mentoring the financial risk protection and equity perspective. However, a significant gap in the monitoring framework related to service coverage was observed. Although Bangladesh has a significant burden of mental illnesses, cataract, and neglected tropical diseases, indicators related to these issues were absent in Bangladesh's UHC framework. Moreover, palliative-care-related indicators were completely missing in the framework. The results of this review suggest that Bangladesh should incorporate these indicators in their UHC monitoring framework in order to track the progress of the country toward UHC more efficiently and in a robust way.

Categories: Preventive Medicine, Miscellaneous, Public Health

Keywords: universal health coverage, monitoring framework, bangladesh

\section{Introduction And Background}

Universal Health Coverage (UHC) is a revolutionary concept adopted by World Health Organization (WHO) and recently incorporated as a target in Sustainable Development Goal (SDG) [1-2]. The basic concept of UHC is, without suffering any financial hardship, all people should have access to quality health care according to their needs. UHC has three dimensions: population coverage, quality service coverage (including preventive, curative, promotive, palliative, and rehabilitative health care services), and financial risk protection [3-5].

Received 12/28/2017

Review began 01/03/2018

Review ended 01/04/2018

Published 01/08/2018

C Copyright 2018

Gupta et al. This is an open access article distributed under the terms of the

Creative Commons Attribution License CC-BY 3.0., which permits unrestricted use, distribution, and reproduction in any medium, provided the original author and source are credited.
UHC is a crying need in the current age, where half of the world population is deprived of the service they need and only half of the covered services has financial protection [6]. The situation is the worst in all dimensions of South East Asia, including Bangladesh [3-7].

In Bangladesh, an inequity exists among the health indicators of different socio-economic groups and geographical locations [8-11]. Currently, in Bangladesh, among the total health expenditure, $64 \%$ is paid out of pocket [7]. Every year, almost $4 \%$ of the population is impoverished due to high out-of-pocket expenditure [12-13]. Catastrophic health expenditure is highest in Bangladesh among the countries of the Asia Pacific region [14]. Therefore, introducing and implementing the concept of UHC is necessary for Bangladesh. The Government of Bangladesh (GOB) is determined to achieve UHC, which is also manifested by the recent adoption of the UHC progress monitoring framework [2].

Measuring progress toward UHC is necessary to know whether the country is on the right track to achieve UHC. Measuring and monitoring the progress will enable policymakers to identify the gaps and help them plan future activities [3]. Therefore, it is very important to create an effective framework to measure and monitor the progress of UHC.

How to cite this article

Gupta R, Shahabuddin A (January 08, 2018) Measuring Progress Toward Universal Health Coverage: Does the Monitoring Framework of Bangladesh Need Further Improvement?. Cureus 10(1): e2041. DOI 10.7759/cureus.2041 


\section{Cureus}

Considering the importance of the issue, this review aimed to explore the UHC monitoring approaches undertaken and the recommendations at the global level, compare those approaches, recommendations, and challenges with the UHC progress monitoring framework adapted by Bangladesh, find out if any gap exists in Bangladesh's UHC progress monitoring framework, and address those gaps for further improvement.

\section{Review}

\section{Methods}

A thorough search of the relevant literature published and available in PubMed and Google Scholar was conducted using the preferred reporting items for systematic reviews and meta-analyses (PRISMA) checklist independently by two researchers (RDG and ASMSU) [15]. The following search terms were used: 'Universal Health Coverage,' 'UHC' in combination with 'global monitoring,' 'global monitoring framework,' 'measurement,' 'Bangladesh,' and 'country level monitoring.' In addition, we manually searched gray literature from the Ministry of Health and Family Welfare (MOHFW), Directorate General of Health Services (DGHS), and Directorate General of Family Planning (DGFP) of Bangladesh. Those articles in the English language and published between January 1, 2005 (the year the World Health Assembly passed a resolution for addressing universal health coverage) to June 15, 2016, were searched [16].

Relevant information from the selected articles was extracted and put in a matrix. A data analysis was done according to the three dimensions of UHC: service coverage, financial protection coverage, and population coverage or equity measurements [3]. Under each dimension, the global and Bangladesh indicators were listed and analyzed thematically.

\section{Results}

\section{Search Results}

After a comprehensive search using the selected keywords, we found 87 reports and articles. Among them, five were excluded after duplication checking and 26 were excluded after reading the titles. Another 19 were excluded after reading the abstract and executive summary. A total of 37 articles and reports were retrieved for further, detailed evaluation. Among them, four articles were selected for the final synthesis. Among these four articles, three were reports and one was a journal article (Figure 1). One report was from Bangladesh (Framework for monitoring progress towards universal health coverage in Bangladesh) [2]. The other three reports and articles described the global-level framework [3,5,17]. 


\section{Cureus}

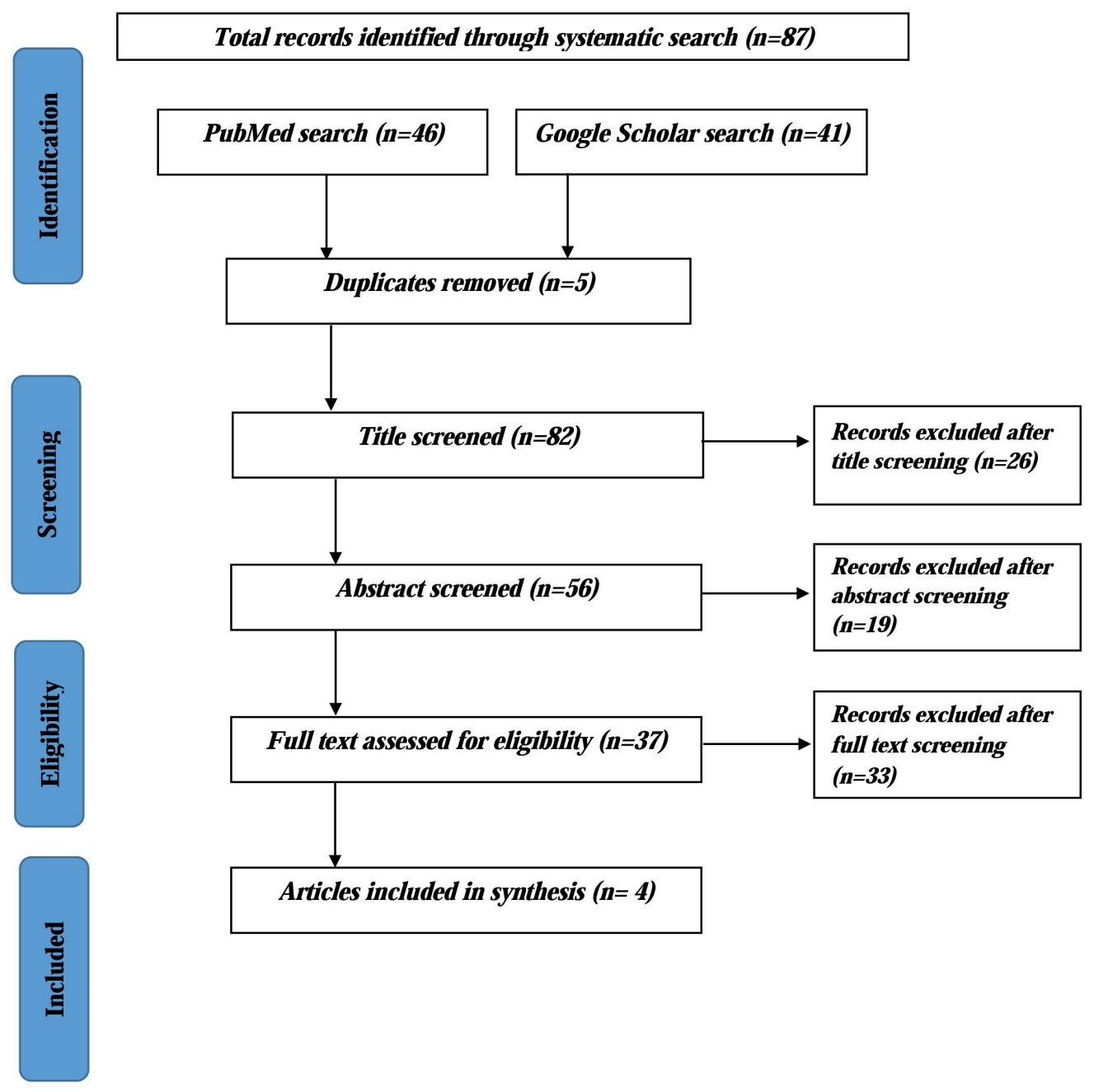

FIGURE 1: Flow Chart Showing the Literature Search and Selection Process

Principles of Measurement and Targets

Principles of measurement: The Bangladesh framework included 47 indicators, including inputs (health workforce, infrastructure, medicines, health information, and research and health care financing), outputs (service access and readiness and service quality and safety), outcome (coverage of intervention, risk factors and behaviors, and health care financing), and impact (improved health status and health/financial security) [2]. Like the global framework, the Bangladesh framework would track progress using outcome indicators and by measuring the equity perspective $[2,5]$.

Targets: Although the global-level framework wanted to achieve the targets of UHC by 2030, Bangladesh set the deadline by 2032 [2,5]. The Bangladesh framework aspired to provide everyone, irrespective of socioeconomic condition, place of residence, and gender, at least $80 \%$ of the essential health services coverage and $100 \%$ protection from financial risks while seeking health services [2].

Measurement of Progress Towards UHC

(a) Curative intervention coverage: For curative intervention coverage, Bangladesh incorporated most of the indicators related with infectious diseases (tuberculosis treatment coverage) and non-communicable diseases (diabetic and hypertension treatment coverage) [2-3]. Additionally, indicators related to acute 


\section{Cureus}

respiratory infection (ARI) treatment coverage were also being added to the Bangladesh framework [2]. Although the global framework suggested antiretroviral therapy coverage, this was not added to the Bangladesh framework [2-3]. Indicators related to mental health and eye health were not incorporated in the Bangladesh framework (Table 1) [2-3].

\section{Comparison of the Global and Bangladesh Frameworks}

Global-Level Recommendations

Curative intervention coverage:

Infectious Diseases: 1. Antiretroviral therapy coverage [3]

2. Tuberculosis treatment coverage [3]

Non-Communicable Diseases (NCDs):

1. Hypertension coverage [3] 2. Diabetes coverage [3]

Mental health: Depression treatment coverage [3]

Eye Health:

Cataract surgical coverage [3]

Preventive Interventions Coverage:

Reproductive and Newborn Health:

1.Family planning coverage with modern methods [3] 2.

Antenatal care coverage [3] 3. Skill birth attendance [3]

\section{Child Immunization:}

1. DPT-3 immunization coverage among one-year-old children [3]

Infectious Diseases:

1. Malaria protection coverage [3]

Tobacco Use: 1. Prevalence of no tobacco smoking in the past 30 days among adults age $\geq 15$ years [3]

Non-Health Sector Determinants of Health:1.

Percentage of population using improved drinking water sources [3] 2. Percentage of population using improved sanitation facilities [3]

Neglected Tropical Diseases (NTDs): 1. Preventive chemotherapy coverage against neglected tropical diseases (NTDs) [3]

\section{Palliative Care Coverage:}

1. Morphine-equivalent consumption of strong opioid analgesics (excluding methadone) per death from cancer [3]

Financial Risk Protection:

1. Catastrophic health expenditures [3] 2. Impoverishing health expenditures [3].

\section{Bangladesh UHC Monitoring Framework}

Infectious Diseases: 1. Tuberculosis treatment coverage: Tuberculosis treatment success rate [2]. 2. Acute respiratory infection (ARI) treatment coverage: Case fatality rate among hospitalized ARI cases [2]

Non-Communicable Diseases (NCDs):

1. Percentage of diabetic and hypertensives receiving treatment/Listed under impact indicators) [2]

2. Mental health: No indicator found

Eye Health: No indicator found

Reproductive and Newborn Health:

1. Family planning coverage: Contraceptive prevalence rate [2] 2.

Antenatal care coverage: Percentage of pregnant women attending four antenatal care checkups [2] 3. Skill birth attendance: Percentages of institutional delivery [2]

Child Immunization:

1. Petavalent-3 immunization coverage among under one-year-old children [2]

Infectious Diseases: 1. Malaria protection coverage: Insecticide-treated bed net coverage among malaria endemic zone [2]

Tobacco Use: No indicator found

Non-Health Sector Determinants of Health:1. Percentage of households with access to safe water [2]

2. Percentage of households with access to improved sanitation [2]

Neglected Tropical Diseases (NTDs): No indicator found
1. Catastrophic health expenditures: Incidence of catastrophic health expenditures (households \%) [2] 2. Impoverishing health expenditures: Incidence of impoverishment due to out-of-pocket health expenditures (populations \%) [2] 


\section{Cureus}

Equity Measurement:

Following aspects of disaggregation where applicable $[3,17]$. 1. Economic status 2. Urban/rural residence 3.

Gender 4. Education
Three main aspects of disaggregation:

1. Economic Status [2] 2. Urban/ rural residence [2]

3. Gender: Also focuses on the disadvantaged group of the population

[2]

\section{TABLE 1: Comparison Between the Global and Bangladesh Frameworks}

UHC: Universal Health Coverage

DPT: Diphtheria, Tetanus, and Pertussis Vaccine

Petavalent: Diphtheria, Tetanus, Pertussis, Haemophilus Influenza Type B, and Hepatitis B Vaccine

(b) Preventive intervention coverage: Bangladesh incorporated most of the indicators recommended by the global framework, including reproductive and neonatal health, child immunization, infectious diseases, and non-health sector determinants of health [2-3]. No indicator was found regarding preventive interventions related to tobacco use and neglected tropical diseases (NTDs) (Table 1) [2-3].

(c) Palliative care coverage: Although monitoring palliative care coverage was recommended by the global framework, Bangladesh did not include that in the UHC monitoring framework (Table 1) [2-3].

(d) Financial risk protection: Bangladesh followed the globally recommended indicators (incidence of catastrophic health expenditures and impoverishing health expenditures) for measuring financial risk protection (Table 1) [2-3].

(e) Equity measurement: Bangladesh followed economic status, urban/rural residence, and gender as part of measuring equity, which is the same as the global framework [2-3]. Furthermore, Bangladesh's framework focuses on the disadvantaged group of the population (people living in the char and hilly areas, and people belonging to minority communities) as a part of monitoring equity (Table 1) [2].

\section{Discussion}

This review compared the UHC monitoring framework of Bangladesh with that of the global community. Coupled with media coverage and the effect of adjacent countries, UHC has been taken into consideration at the policy level in Bangladesh [7]. In 2012, Bangladesh introduced its first health financing strategy with the aim to achieve UHC by 2032 [18]. Later, in 2014, the government of Bangladesh formulated a monitoring framework for UHC [2].

This review identified some of the gaps in monitoring service coverage. Bangladesh has adopted UHC monitoring indicators according to its epidemiological context. The HIV-related indicator was excluded and the ARI-related indicator was included due to the low and high prevalence of the diseases, respectively [1921]. Bangladesh is facing an epidemiologic transition like many other countries with an increasing burden of non-communicable diseases (NCDs) [22-24]. Currently, 61\% of all deaths in Bangladesh are attributed to NCDs [25]. Although the global level has recommended NCD (especially diabetes and hypertension) related indicators in the intervention coverage, Bangladesh did not include those indicators; rather, it included them under impact indicators. This is because Bangladesh does not have any full-scale program exclusively for NCDs; rather, these indicators would assess the NCD treatment coverage provided by various health care providers [26-27].

Bangladesh did not have any indicator regarding the monitoring of the mental diseases' treatment coverage although it has a significant burden of mental diseases [26,28]. A systematic review found that about $6.5 \%$ to $31 \%$ of Bangladeshi adults were suffering from different types of psychiatric disorders. This burden ranged from $13.4 \%$ to $22.9 \%$ for the children in Bangladesh [28]. The ignorance of indicators related to mental health is a gap in the UHC monitoring framework of Bangladesh, which needs to be addressed.

The global framework has recommended cataract surgical coverage as an indicator [3]. Although cataract is 
the main cause (79.6\%) of avoidable blindness among the adult Bangladeshi population, the coverage of cataract surgical is currently low (32.5\%) in Bangladesh; moreover, there is geographical inequity in treatment coverage [29-30]. Although Bangladesh introduced 'National Eye Care Plan' in 2005 followed by several revisions, the national UHC monitoring framework still did not include cataract surgical coverage $[29]$.

Although the global-level framework has recommended to include tobacco quit rate as a UHC monitoring indicator, Bangladesh did not incorporate any indicators related to tobacco quit rate [2-3]. Rather, the framework included tobacco prevalence rate as an indicator [2]. This is may be due to the lack of planned interventions against tobacco use in Bangladesh. Currently, Bangladesh has a huge burden of tobacco use. As per the estimate of a nationwide survey conducted in 2010, 54\% of the Bangladeshi population above the age of 25 years was using some form of tobacco [30]. The prevalence rate was even higher (64\%) in urban slums, as revealed by a recent study [31]. Bangladesh has an act that bans any sort of advertisement of tobacco products. Recently, Bangladesh has introduced plain packaging of tobacco products [27,32]. Previous findings suggest that the laws against tobacco consumption are not being enacted effectively in Bangladesh [33].

Bangladesh has a burden of several neglected tropical diseases (NTDs), including visceral leishmaniasis (kala-azar), lymphatic filariasis, dengue/dengue hemorrhagic fever, rabies, and snake bite [21,34-36]. Still, NTDs were ignored in the UHC monitoring framework of Bangladesh. Bangladesh has been implementing mass drug administration (MDA) as part of preventive chemotherapy coverage against lymphatic filariasis [21]. Rabies prevention and control programs are also ongoing [21]. These indicators could be included in the UHC monitoring framework to track the situation of such programs and diseases.

The indicator related to palliative care was ignored in Bangladesh's UHC monitoring framework. Palliative care services are very limited in Bangladesh [26]. With the absence of this indicator, one of the important dimensions of service delivery will remain unknown to policymakers and public health managers.

\section{Conclusions}

Bangladesh's UHC monitoring framework successfully adopted a majority of the indicators recommended by the global-level UHC framework. However, significant gaps still exist in Bangladesh's monitoring framework, creating an opportunity for improvement. Indicators related to palliative care, mental health, cataract surgery, neglected tropical diseases, and measurement of service need should be included in Bangladesh's UHC monitoring framework. An explicitly defined framework with a comprehensive set of indicators will help Bangladesh track its progress toward achieving UHC, and compare its status with other countries.

\section{Additional Information \\ Disclosures}

Conflicts of interest: In compliance with the ICMJE uniform disclosure form, all authors declare the following: Payment/services info: All authors have declared that no financial support was received from any organization for the submitted work. Financial relationships: All authors have declared that they have no financial relationships at present or within the previous three years with any organizations that might have an interest in the submitted work. Other relationships: All authors have declared that there are no other relationships or activities that could appear to have influenced the submitted work.

\section{References}

1. Tangcharoensathien V, Mills A, Palu T: Accelerating health equity: the key role of universal health coverage in the sustainable development goals. BMC Med. 2015, 13:101. 10.1186/s12916-015-0342-3

2. Framework for monitoring progress towards universal health coverage in Bangladesh . (2014). Accessed: June 18, 2017: http://heu.gov.bd/pdf/UHC_indicators\%20FINAL.pdf.

3. Tracking universal health coverage: first global monitoring report. (2015). Accessed: June 18, 2017: http://apps.who.int/iris/bitstream/10665/174536/1/9789241564977_eng.pdf.

4. Wagstaff A, Cotlear D, Eozenou PHV, Buisman LR: Measuring progress towards universal health coverage: with an application to 24 developing countries. Oxford Rev Econ Pol. 2016, 32:147-189. 10.1093/oxrep/grv019

5. Monitoring progress towards universal health coverage at country and global levels: framework, measures and targets. (2014). Accessed: June 18, 2017: 
http://apps.who.int/iris/bitstream/10665/112824/1/WHO_HIS_HIA_14.1_eng.pdf.

6. Boerma T, Eozenou P, Evans D, Evans T, Kieny MP, Wagstaff A: Monitoring progress towards universal health coverage at country and global levels. PLoS Med. 2014, 11:e1001731. 10.1371/journal.pmed.1001731

7. Huda T, Khan JAM, Ahsan KZ, Jamil K, El Arifeen S: Monitoring and evaluating progress towards universal health coverage in Bangladesh. PLoS Med. 2014, 11:e1001722. 10.1371/journal.pmed.1001722

8. Huda TM, Tahsina T, El Arifeen S, Dibley MJ: The importance of intersectoral factors in promoting equityoriented universal health coverage: a multilevel analysis of social determinants affecting neonatal infant and under-five mortality in Bangladesh. Glob Health Action. 2016, 9:29741. 10.3402/gha.v9.29741

9. Adams AM, Ahmed T, El Arifeen S, Evans TG, Huda T, Reichenbach L: Innovation for universal health coverage in Bangladesh: a call to action. Lancet. 2014, 382:2104-2111. 10.1016/S0140-6736(13)62150-9

10. Adams AM, Islam R, Ahmed T: Who serves the urban poor? A geospatial and descriptive analysis of health services in slum settlements in Dhaka, Bangladesh. Health Policy Plan. 2015, 30:i32-i45. 10.1093/heapol/czu094

11. Biswas T, Islam MS, Linton N, Rawal LB: Socio-economic inequality of chronic non-communicable diseases in Bangladesh. PLoS One. 2016, 11:0167140. 10.1371/journal.pone.0167140

12. Van Doorslaer E, O'Donnell O, Rannan-Eliya RP, et al.: Effect of payments for health care on poverty estimates in 11 countries in Asia: an analysis of household survey data. Lancet. 2006, 368:1357-1364. 10.1016/S0140-6736(06)69560-3

13. Joarder T, Sarker M: Achieving universal health coverage through community empowerment: a proposition for Bangladesh. Indian J Community Med. 2014, 39:129. 10.4103/0970-0218.137143

14. Van Doorslaer E, O'Donnell O, Rannan-Eliya RP, et al.: Catastrophic payments for health care in Asia. Health Econ. 2007, 16:1159-1184. 10.1002/hec.1209

15. Liberati A, Altman DG, Tetzlaff J, et al.: The PRISMA statement for reporting systematic reviews and metaanalyses of studies that evaluate health care interventions: explanation and elaboration. PLoS Med. 2009, 6:e1000100. 10.1371/journal.pmed.1000100

16. Sustainable health financing, universal coverage and social health insurance . (2005). Accessed: June 18, 2017: http://apps.who.int/medicinedocs/documents/s21475en/s21475en.pdf.

17. Hosseinpoor AR, Bergen N, Koller T, et al.: Equity-oriented monitoring in the context of universal health coverage. PLoS Med. 2014, 11:e1001727. 10.1371/journal.pmed.1001727

18. Expanding social protection for health: towards universal coverage-health care financing strategy 20122032. (2012). Accessed: June 18, 2017: http://www.heu.gov.bd/pdf/Health\%20Care\%20Financing\%20Strategy\%202012-2032.pdf.

19. Nasreen S, Luby SP, Brooks WA, et al.: Population-based incidence of severe acute respiratory virus infections among children aged< 5 years in rural Bangladesh, June-October 2010. PLoS Med. 2014, 9:e89978. 10.1371/journal.pone.0089978

20. Rahman MM, Shahidullah M: Risk factors for acute respiratory infections among the slum infants of Dhaka city. Bangladesh Med Res Counc Bull. 2001, 27:55-62.

21. Health Bulletin 2016. (2017). Accessed: May 1, 2017: http://www.dghs.gov.bd/images/docs/Publicaations/HB\%202016\%20_2nd_edition_13_01_17.pdf.

22. Ahsan Karar Z, Alam N, Streatfield PK: Epidemiological transition in rural Bangladesh, 1986-2006. Glob Health Action. 2009, 2:1904. 10.3402/gha.v2i0.1904

23. Mascie-Taylor N: Is Bangladesh going through an epidemiological and nutritional transition? . Coll Antropol. 2012, 36:1155-1159.

24. Amuna P, Zotor FB: Epidemiological and nutrition transition in developing countries: impact on human health and development. Proc Nutr Soc. 2008, 67:82-90. 10.1017/S0029665108006058

25. Health systems preparedness for responding to the growing burden of non-communicable disease-a case study of Bangladesh. (2013). Accessed: October 27, 2017:

http://ni.unimelb.edu.au/_data/assets/pdf_file/0008/720656/WP25.pdf.

26. Bangladesh health system review. (2015). Accessed: June 1, 2016: http://iris.wpro.who.int/bitstream/handle/10665.1/11357/9789290617051_eng.pdf.

27. Biswas T, Pervin S, Tanim MIA, Niessen L, Islam A: Bangladesh policy on prevention and control of noncommunicable diseases: a policy analysis. BMC Public Health. 2017, 17:582. 10.1186/s12889-017-4494-2

28. Hossain MD, Ahmed HU, Chowdhury WA, Niessen LW, Alam DS: Mental disorders in Bangladesh: a systematic review. BMC Psychiatry. 2014, 14:216. 10.1186/s12888-014-0216-9

29. National eye care plan 2020. (2011). Accessed: June 1, 2016: http://ssmfbd.org/images/pdf/national_eye_care.pdf.

30. Non-communicable disease risk factor survey Bangladesh 2010 . (2011). Accessed: October 27, 2017: http://www.searo.who.int/bangladesh/publications/ncd_risk_factor_2010/en/.

31. Khandker NN, Biswas T, Khan ANS, Hasib E, Rawal LB: Socio-demographic characteristics and tobacco use among the adults in urban slums of Dhaka, Bangladesh. Tob Induc Dis. 2017, 15:26. 10.1186/s12971-0170131-1

32. An act for the amendment of smoking and tobacco products usage (control) act . (2005). Accessed: October 27, 2017: https://www.tobaccocontrollaws.org/files/live/Bangladesh/Bangladesh\%20\%20TC\%20Amdt.\%20Act\%202013.pdf.

33. ITC Bangladesh report on smoke-free policies: findings from the Wave 1 (2009) and Wave 2 (2010) surveys . 


\section{Cureus}

(2011). Accessed: October 27, 2017:

http://www.itcproject.org/files/Report_Publications/National_Report/itcbdsmokefreereportfinalwebmay2011.

34. Chowdhury F-R, Basher A, R Amin M, et al.: Rabies in South Asia: fighting for elimination . Recent Pat Antiinfect Drug Discov. 2015, 10:30-34.

35. A situation analysis: neglected tropical diseases in Bangladesh . (2010). Accessed: October 27, 2017: http://pdf.usaid.gov/pdf_docs/pnady849.pdf.

36. Rahman R, Faiz MA, Selim S, et al.: Annual incidence of snake bite in rural Bangladesh . PLoS Negl Trop Dis. 2010, 4:e860. 10.1371/journal.pntd.0000860 